\title{
Automated Solid-Phase Protein Modification with Integrated Enzymatic Digest for Reaction Validation: Application of a Compartmented Microfluidic Reactor for Rapid Optimization and Analysis of Protein Biotinylation
}

\author{
Regina Fraas, Juliane Diehm and Matthias Franzreb* \\ Institute of Functional Interfaces, Karlsruhe Institute of Technology, Karlsruhe, Germany
}

\section{OPEN ACCESS}

Edited by:

Florent Allais,

AgroParisTech Institut des Sciences

et Industries du Vivant et de

L'environnement, France

Reviewed by:

Christophe Len,

University of Technology of

Compiègne, France

Marine Janvier,

ParisTech Institut des Sciences et

Technologies, France

*Correspondence:

Matthias Franzreb

matthias.franzreb@kit.edu

Specialty section:

This article was submitted to

Chemical Engineering,

a section of the journal

Frontiers in Bioengineering

and Biotechnology

Received: 17 June 2017

Accepted: 31 October 2017

Published: 13 November 2017

Citation:

Fraas R, Diehm J and Franzreb $M$ (2017) Automated Solid-Phase Protein Modification with Integrated

Enzymatic Digest for Reaction

Validation: Application of a Compartmented Microfluidic Reactor for Rapid Optimization and Analysis of Protein Biotinylation.

Front. Bioeng. Biotechnol. 5:72. doi: 10.3389/fbioe.2017.00072
Protein modification by covalent coupling of small ligands or markers is an important prerequisite for the use of proteins in many applications. Well-known examples are the use of proteins with fluorescent markers in many in vivo experiments or the binding of biotinylated antibodies via biotin-streptavidin coupling in the frame of numerous bioassays. Multiple protocols were established for the coupling of the respective molecules, e.g., via the $\mathrm{C}$ and $\mathrm{N}$-terminus, or via cysteines and lysines exposed at the protein surface. Still, in most cases the conditions of these standard protocols are only an initial guess. Optimization of the coupling parameters like reagent concentrations, $\mathrm{pH}$, or temperature may strongly increase coupling yield and the biological activity of the modified protein. In order to facilitate the process of optimizing coupling conditions, a method was developed which uses a compartmented microfluidic reactor for the rapid screening of different coupling conditions. In addition, the system allows for the integration of an enzymatic digest of the modified protein directly after modification. In combination with a subsequent MALDI-TOF analysis of the resulting fragments, this gives a fast and detailed picture not only of the number and extent of the generated modifications but also of their position within the protein sequence. The described process was demonstrated for biotinylation of green fluorescent protein. Different biotin-excesses and different $\mathrm{pH}$-values were tested in order to elucidate the influence on the modification extent and pattern. In addition, the results of solid-phase based modifications within the microfluidic reactor were compared to modification patterns resulting from coupling trials with unbound protein. As expected, modification patterns of immobilized proteins showed clear differences to the ones of dissolved proteins.

Keywords: protein modification, solid-phase reaction, enzymatic digest, microfluidic reactor, biotinylation

\section{INTRODUCTION}

The synthetic modification of proteins has many applications in biotechnology. By use of chemiluminescent or fluorescent dyes proteins can be made visible in vitro and in vivo (Gillespie and Hudspeth, 1991; Ballou et al., 1995; Han et al., 2015; Press et al., 2016). Physicochemical properties (solubility, stability) can be altered (Xiao et al., 2008; Morgenstern et al., 2017), or proteins can be 
activated for immobilization or cross-linking (Tang and Bruce, 2009; Hutsell et al., 2010). A comprehensive and detailed collection of modification reactions and protocols were given in several books and publications (Wu and Goody, 2010; Hermanson, 2013; Boutureira and Bernardes, 2015).

For protein immobilization, biotin plays an important role. Biotin is a 244.31-Da molecule, which takes part in important metabolic processes in nature (McMahon, 2002). It is known for its unusually strong non-covalent interaction with avidin. The dissociation constant is $10^{-15} \mathrm{M}$ (Guesdon et al., 1979) and is thus higher than the one of antibodies and their antigen (Diamandis and Christopoulos, 1991). Avidin is a 66-kDa glycoprotein from eggwhite, consisting of four subunits with $16.4 \mathrm{kDa}$ each (Green, 1975). Each subunit is capable of binding one biotin.

Due to the strong bond between biotin and avidin, the biotinylation of proteins is used for affinity chromatography, immunoassays, or immobilization. A well-established reaction for the biotinylation of proteins is the use of reactive groups like the amine-reactive $N$-hydroxysuccinimide (NHS) or the sulfur-reactive maleimide. The structure of biotin-NHS is given in Figure 1. NHS-biotin reacts mainly with the terminal amine or lysines, which are present on the surface of proteins with high frequency (Sokalingam et al., 2013). The reactivity of NHS groups depends on multiple factors like $\mathrm{pH}$-value or temperature which influence the amount of modified lysines. For each protein, screening of these conditions is a necessary prerequisite for yield optimization, but can be time consuming. We developed a compartmented, microfluidic reactor system which allows the parallel evaluation of several reaction conditions for biotinylation. A subsequent on-line enzymatic digest followed by an off-line mass spectrometric measurement allows a fast and detailed analysis of the resulting reaction products.

Compartmentalization of the reactor is achieved in the reaction capillary by inserting aqueous reaction phases followed by nonmixable (organic) solvents or air. For protein modification, the reaction phases consist of aqueous buffers filled with reactants or enzymes. The target protein is immobilized on magnetic particles and can be transported through the reactor. A relative movement between plugs and the immobilized protein is achieved by fixing the magnetic particles with an external bar magnet and pumping the reactor content further until the desired plug is reached. Thus, the particles can sequentially enter reaction plugs filled with different reactants and react accordingly. In Hübner et al. (2015), a precursor of the reactor was presented. In this study, we show an important enhancement of the reactor and its use

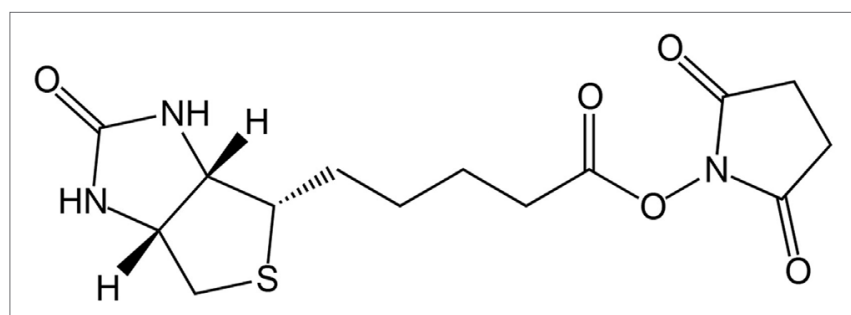

FIGURE 1 | Chemical structure of N-hydroxysuccinimide (NHS)-biotin. for the screening of biotinylation conditions. Experiments with free eGFP were conducted under the same conditions in order to show whether differences in the isomer formation occur for the immobilized protein.

\section{MATERIALS AND METHODS}

\section{Chemicals and Materials}

Chemicals used for this work are given in the following. Sinapic acid, $\alpha$-cyano-4-hydroxycinnamic acid (CHCA), pepsin from porcine pancreas, trifluoroacetic acid (TFA), biotin NHS ester (NHS-Biotin), and ammonium bicarbonate $\left(\mathrm{NH}_{4} \mathrm{HCO}_{3}\right)$ were purchased from Sigma Aldrich (St. Louis, MO, USA), Pierce BCA protein assay kit from Thermo Scientific (Waltham, MA, USA).

Albumin fraction $\mathrm{V}$ from bovine serum, sodium dihydrogen phosphate dihydrate, ethanolamine, copper(II) sulfate pentahydrate, hydrochloric acid (32\%), pH-indicator strips MColorpHast ( $\mathrm{pH}$ 0-14), $\mathrm{pH}$-indicator strips $\mathrm{pH}$ 5-10, and sodium chloride were purchased from Merck Millipore (Darmstadt Germany); dimethyl sulfoxide (DMSO) from VWR (Radnor, PA, USA). Disodium hydrogen phosphate and sodium hydroxide were ordered from Carl Roth GmbH \& Co. KG (Karlsruhe, Germany); disuccinimidyl suberate (DSS) was ordered from Cayman Chemical Company (Ann Arbor, MI, USA).

The plasmid for eGFP production was generated at the Institute of Industrial Genetics of the University of Stuttgart, Germany. The plasmid pJOE4056 was used as vector for the fusion of the (His) 6-tag. The protein was expressed by Escherichia coli (E. coli) BW3110 at the Institute of Biochemical Engineering of the University of Stuttgart, Germany. Fermentation was conducted as described by Wilms et al. (2001).

Magnetic micro particles with iminodiacetic acid functionalization (IDA-particles), with carboxy functionalization (C22) and with $\mathrm{N}, \mathrm{N}$-diethyl-1,3-propanediamine functionalization (DEAP) were kindly donated by PerkinElmer chemagen Technologie $\mathrm{GmbH}$ (Baesweiler, Germany). Capillaries consisted of fluorinated ethylene propylene and were purchased from Wolf-Technik (Stuttgart, Germany) with an outer diameter of $3.17 \mathrm{~mm}$ and an inner diameter of $1.58 \mathrm{~mm}$.

\section{Analytical Methods}

\section{Protein Immobilization and Quantification}

The concentration of the bead suspension was determined gravimetrically before protein immobilization. For this, $200 \mu \mathrm{L}$ of the bead suspension were dried at $60^{\circ} \mathrm{C}$ in triplicates in pre-weighed HPLC glass vials in a drying oven Heraeus Function Line serie 7000 B6 from Heraeus (Hanau, Germany). After drying of the particles, vials were weighed again on a microbalance Sartorius MC 5 (Göttingen, Germany) and the concentration was calculated. eGFP with His-tag was immobilized on IDA-functionalized particles. The particles were first activated with a solution of $50 \mathrm{mM} \mathrm{CuSO}_{4}, 0.2 \mathrm{M} \mathrm{NaCl}, \mathrm{pH} 4.2$ (activation solution). $10 \mathrm{mg}$ particles were mixed with $1.5 \mathrm{~mL}$ activation solution at $25^{\circ} \mathrm{C}$ and 1,400 rpm for $1 \mathrm{~h}$. Particles were washed with $50 \mathrm{mM}$ phosphate buffer $\mathrm{pH} 7.5$ (storage buffer) once and between 0.3 and $1.6 \mathrm{mg}$ protein in solution were added. Immobilization was conducted 
for $1 \mathrm{~h}$ at $25^{\circ} \mathrm{C}$ and $1,400 \mathrm{rpm}$. A Thermomixer comfort 5355 by Eppendorf AG (Hamburg, Germany) was used for mixing and tempering of immobilization and modification reactions in reaction vessels.

Afterward, the beads were washed with $10 \mathrm{mM}$ phosphate buffer, $0.8 \mathrm{M} \mathrm{NaCl}, \mathrm{pH} 7.5$ (washing buffer) three times, twice with storage buffer and the supernatants were collected. By use of a BCA-Assay protein concentrations in the washing supernatants and the eGFP stock solution were determined. BSA solutions with different concentrations in the same buffer were applied for calibration. Absorption was measured in multititer plates with 96 wells from Brand (Wertheim, Deutschland) in a plate reader EnSpire 2300 Multimode from PerkinElmer (Waltham, MA, USA).

Protein loading was calculated from the difference of the protein mass applied for immobilization $\left(m_{\text {Protein }}\right)$ and the protein mass not bound ( $\left.m_{\text {Protein, supernatant }}\right)$ and washed off $\left(m_{\text {Protein, wash }}\right)$. The difference was divided by the particle mass ( $\left.m_{\text {Particle }}\right)$, as described in Eq. 1.

$$
\text { Load }=\frac{m_{\text {Protein }}-\left(m_{\text {Protein,Supernatant }}+m_{\text {Protein, Wash }}\right)}{m_{\text {Particle }}}
$$

\section{Mass Spectrometric Measurements}

Mass spectrometric measurements were performed in a MALDI TOF/TOF 4800 analyzer (Applied Biosystems, Framingham, MA, USA), either in linear mode or in reflector mode. Samples for MALDI-measurements were diluted 1:25 with the matrix solution. For the linear mode, $10 \mathrm{mg} / \mathrm{mL}$ sinapic acid in $50 \%(\mathrm{v} / \mathrm{v})$ acetonitrile with $0.1 \%$ TFA were used as matrix, for the reflector mode $10 \mathrm{~g} / \mathrm{L}$ CHCA in 50\% acetonitrile with $1 \%$ TFA. $0.5-1 \mu \mathrm{L}$ of each sample-matrix solution and a calibration mix were spotted onto a MALDI stainless steel target. Dried spots were measured via MALDI TOF/TOF. MALDI measurements were analyzed with Data Explorer Software 4.0 (Applied Biosystems). Further analysis was done with the open source software mmass (Strohalm et al., 2010). Spectra in linear mode were smoothed using a Savitzky-Golay filter with a window size of $50 \mathrm{~m} / \mathrm{z}$ and five cycles in the software "mmass."

For measurements in reflector mode, a list of the peptide masses in the spectrum was generated by the built-in tool in the Data Explorer Software 4.0. In order to prove the successful proteolytic digest of the protein, the generated list was entered in the databank "MASCOT Peptide Mass Fingerprint" (Perkins et al., 1999). This software calculates which organism correlates most with the entered data. For the determination of peptide fragments after an enzymatic digest the tool "PeptideMass" from Expasy was used (Wilkins et al., 1997).

\section{Digest of Free and Immobilized Protein}

The analysis of the modified amino acids requires a fragmentation of the protein, which is achieved here with the protease pepsin. For the digest of immobilized protein $0.3 \mathrm{mg}$ eGFP on IDA-particles were applied. The protein was immobilized and then washed with $0.1 \mathrm{M}$ citrate buffer $\mathrm{pH}$ 2. The buffer was replaced by $100 \mu \mathrm{L}$ of a $1 \mathrm{~g} / \mathrm{L}$ pepsin solution in $0.1 \mathrm{M}$ citrate buffer $\mathrm{pH} 2$. The samples were digested for $21-22 \mathrm{~h}$ at room temperature on a shaker. The reaction was stopped by addition of $30 \mu \mathrm{L}$ of $1 \mathrm{M} \mathrm{NaOH}$ per $100 \mu \mathrm{L}$ sample and prepared for MALDI measurement.

For free protein, buffer exchange was performed using centrifugal concentrators Vivaspin ${ }^{\circledR}$. The buffer of $0.3 \mathrm{mg}$ of free protein was replaced by $0.1 \mathrm{M}$ citrate buffer $\mathrm{pH} 2$ and $100 \mu \mathrm{L}$ of $1 \mathrm{~g} / \mathrm{L}$ pepsin solution were added. The following sample preparation corresponded to the one for immobilized protein.

\section{Determination of Modification Sites}

The enzymatic digest and mass spectrometric analysis of the digest product can be used for determination of the biotinylated lysines. Identification of the modification sites occurred according to a protocol, which is summarized in Figure 2. First, the theoretic cleavage sites of pepsin for eGFP were determined using "PeptideMass" from Expasy. The resulting peptide fragments and their masses were calculated with this information. The mass of bound biotin $(226.078 \mathrm{~g} / \mathrm{mol})$ was added to the theoretic peptide masses and the masses were deposited in a file ("peptides with biotin"). The mass spectra of the unmodified eGFP were compared to the spectra of the modified eGFP afterward in order to find differences. Lists were created with those peptide masses, which were only present in the spectra of the modified proteins ("potentially biotinylated peptides"). The potentially biotinylated peptides were compared to the list of "peptides with biotin." Agreements were only assumed with mass differences below $0.2 \mathrm{Da}$ and with at least one lysine in the peptide sequence. Additionally, it had to be found in all spectra of the triplicates per run. For verification, MS/MS Measurements were performed. MS/MS measurements allow for a more detailed fragmentation of a mass that was found in the spectrum of a sample. This delivers further information about the peptide. A voltage of $1 \mathrm{kV}$ was used for fragmentation. Only if the MS/MS measurements confirmed the modification of a peptide, a successful reaction was assumed.

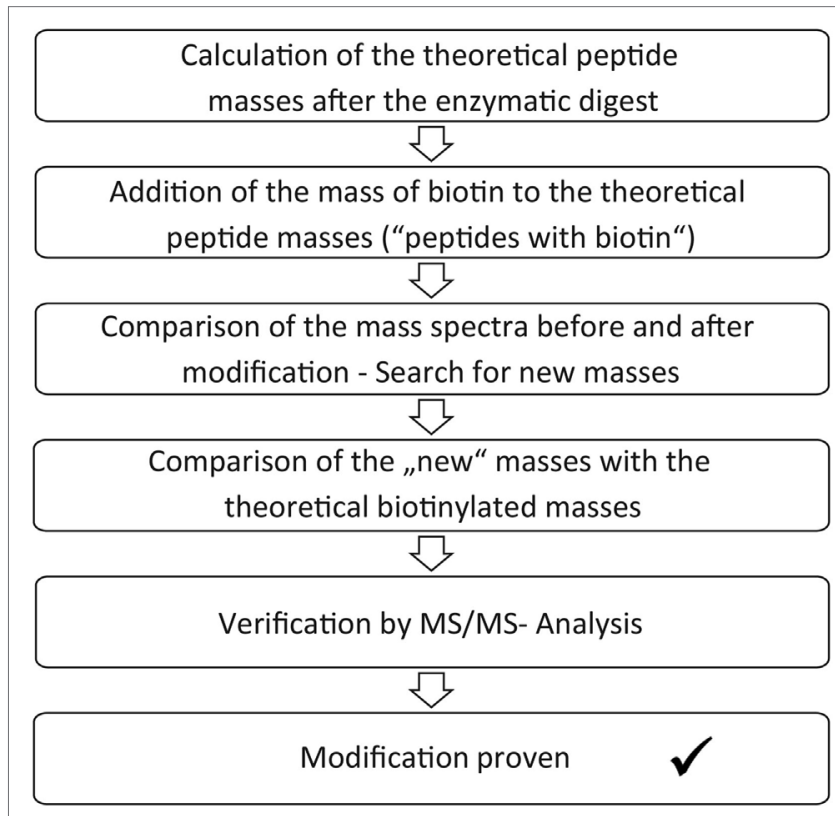

FIGURE 2 | Scheme for analysis of the biotinylated modification sites. 


\section{Protein Modification Reactions}

Protein modification was either performed using different $\mathrm{pH}$ values or different molar excesses of NHS-biotin compared to the applied eGFP. For the excess-experiments NHS-biotin was used in a 10-, 20-, 50-, or 100-fold molar excess compared to the $0.1 \mathrm{mg}$ immobilized protein per reaction. The particles were inserted into the reactor in a $10-\mathrm{g} / \mathrm{L}$ suspension in storage buffer with $15 \%$ DMSO. A stock solution with $1.8 \mathrm{~g} / \mathrm{L}$ Biotin-NHS was made and diluted 1:20 in a solution of $40 \%$ DMSO and $60 \%$ storage buffer. For reduction of the biotin excess the stock solution was further diluted.

Mixing was achieved by pumping $50 \mu \mathrm{L}$ with a flow rate of $20 \mu \mathrm{L} / \mathrm{s}$ forth and back. The digest was performed in the reactor as described in Section "Digest of Free and Immobilized Protein." For comparison, the reaction was also conducted with free protein in micro centrifuge tubes under equal conditions. This reaction was stopped by adding $100 \mu \mathrm{L}$ of an ethanolamine solution $\mathrm{pH} 7$ with a 30 -fold excess compared to biotin.

The experiments for screening of $\mathrm{pH}$-values were performed using $0.3 \mathrm{mg}$ immobilized eGFP. The magnetic particles with the immobilized GFP were pumped into the reactor in a suspension with storage buffer and 15\% DMSO. Depending on the desired $\mathrm{pH}$-value, magnetic ion exchange particles were also pumped into the reactor in another plug. They were then moved to the reaction plug, which contained a 20 -fold molar excess of biotinNHS (compared to $0.3 \mathrm{mg}$ eGFP). By mixing the particles in the reaction plug for $5 \mathrm{~min}$, the $\mathrm{pH}$ was changed as desired (see Change of $\mathrm{pH}$-Value in the Reactor Device). After removal of the ion exchange particles, the particles with the immobilized eGFP were moved to the reaction plug and the modification took place for $5 \mathrm{~min}$. After the reaction, the particles were pumped out of the reactor and washed. The $\mathrm{pH}$-value of the plug was controlled with $\mathrm{pH}$-indicator strips. Half of the particles were used for protein elution in a solution $0.5 \% \mathrm{NH}_{4} \mathrm{HCO}_{3}$ in water twice for $15 \mathrm{~min}$ and measured in linear mode. The other half was digested by pepsin and measured via MALDI in reflector mode. The reaction was also performed with free protein under the same conditions. This reaction was stopped by adding $100 \mu \mathrm{L}$ of an ethanolamine solution $\mathrm{pH} 7$ with a 30 -fold excess compared to biotin and then prepared for digest and analysis as given in Section "Digest of Free and Immobilized Protein."

\section{Change of pH-Value in the Reactor Device}

Magnetic ion exchange particles were used to adjust the $\mathrm{pH}$-value in selected plugs inside the reactor. $3 \mathrm{mg}$ particles with carboxy functionalization (C22) could be used to lower the $\mathrm{pH}$-value of $100 \mu \mathrm{L}$ storage buffer to $\mathrm{pH} 6.5 .3 .8 \mathrm{mg}$ particles with $N, N$ diethyl-1,3-propanediamine functionalization (DEAP) increased the $\mathrm{pH}$-value of $100 \mu \mathrm{L}$ storage buffer to $\mathrm{pH} 8$. C22 particles were first activated by shaking $54 \mathrm{mg}$ particles in $2 \mathrm{~mL} 1 \mathrm{M} \mathrm{HCl}$ for $10 \mathrm{~min} .62 \mathrm{mg}$ DEAP particles were shaken for $10 \mathrm{~min}$ in $2 \mathrm{~mL}$ $1 \mathrm{M} \mathrm{NaOH}$. The particles were washed with MilliQ and stored therein.

\section{Titration Curves of Magnetic Particles}

The titration curves of the magnetic particles were determined as described by Paulus et al. (2015). For this $20 \mathrm{mg}$ particles were washed in a solution of $0.01 \mathrm{M} \mathrm{NaOH}$ and then resuspended in $10 \mathrm{~mL}$ of the same solution. A solution of $0.1 \mathrm{M} \mathrm{HCl}$ was added step-wise. The particles were separated by use of a magnet and the alteration of the $\mathrm{pH}$-value was measured. Both DEAP and C22 particles were used and titration curves were determined twice. The $\mathrm{pKa}$ was determined at the inflection point between the plateaus (Stipanuk and Caudil, 2012). For the DEAP particles, the method of Frimmel et al. (1985) was applied additionally. First, the titration curve for water was substracted from the DEAP titration curve. In order to achieve this, interpolations were performed for the curves, respectively, and the difference of the curves was plotted versus the $\mathrm{pH}$-value. The derivative of the resulting difference plot was formed. For calculating the derivative, the difference plot was approximated to a ninth order polynomic function. The maximums of the derivative plot represent the $\mathrm{pKa}$.

\section{RESULTS AND DISCUSSION}

\section{Reaction Device}

In this study, we present an enhanced version of the reaction device presented in Hübner et al. (2015). A schematic is given in Figure 3. The syringe pump in "pulling mode" pulls the liquids from the reservoir area (storage of buffers, solvents, and reactant solutions) into the reaction area. In the reaction area, the reaction capillaries are arranged between valve 2 and valve 3 and are filled with reaction and separation plugs. Other than depicted in the scheme, each valve contains 10 ports. As two ports of valve 3 serve as output ports, eight reaction capillaries are available for reactions. The syringe pump and the valves are controlled by the software QmixElements (Cetoni, Korbußen, Germany), thus allowing a semi-automated operation of the reaction device.

The main control unit as well as the modules with a syringe pump or multiport valves, respectively, were purchased from cetoni $\mathrm{GmbH}$ (Korbußen, Germany) and consisted of a Qmix base module "BASE 600," three low pressure valve modules "Qmix V EX" and a "neMESYS" low pressure syringe pump. Whereas in former studies only one reaction capillary was present, parallelization is achieved here by use of three valves. This allows for the introduction of eight reaction capillaries which are usable in parallel. This leads to a significant reduction of experiment duration. In the original version of the device mixing of the magnetic beads in the reactor was mainly achieved by Helmholtz coils inducing a magnetic field. In the case of parallelized reaction capillaries efficient mixing is achieved by pumping the reactor content forth and back for a few microliters. The particles are dispersed inside the plug by this movement. This way, scale-up of the electromagnetic coils and the requirement of cooling of the coils is not necessary anymore.

\section{Digest and Identification of the Immobilized Protein}

eGFP is a very stable protein that is hardly digestible at neutral pH-values (Chiang et al., 2001). A digest can, however, be performed in an acidic medium (Alkaabi et al., 2005), e.g., by the protease pepsin at $\mathrm{pH} 2$. This reaction was already used with free 

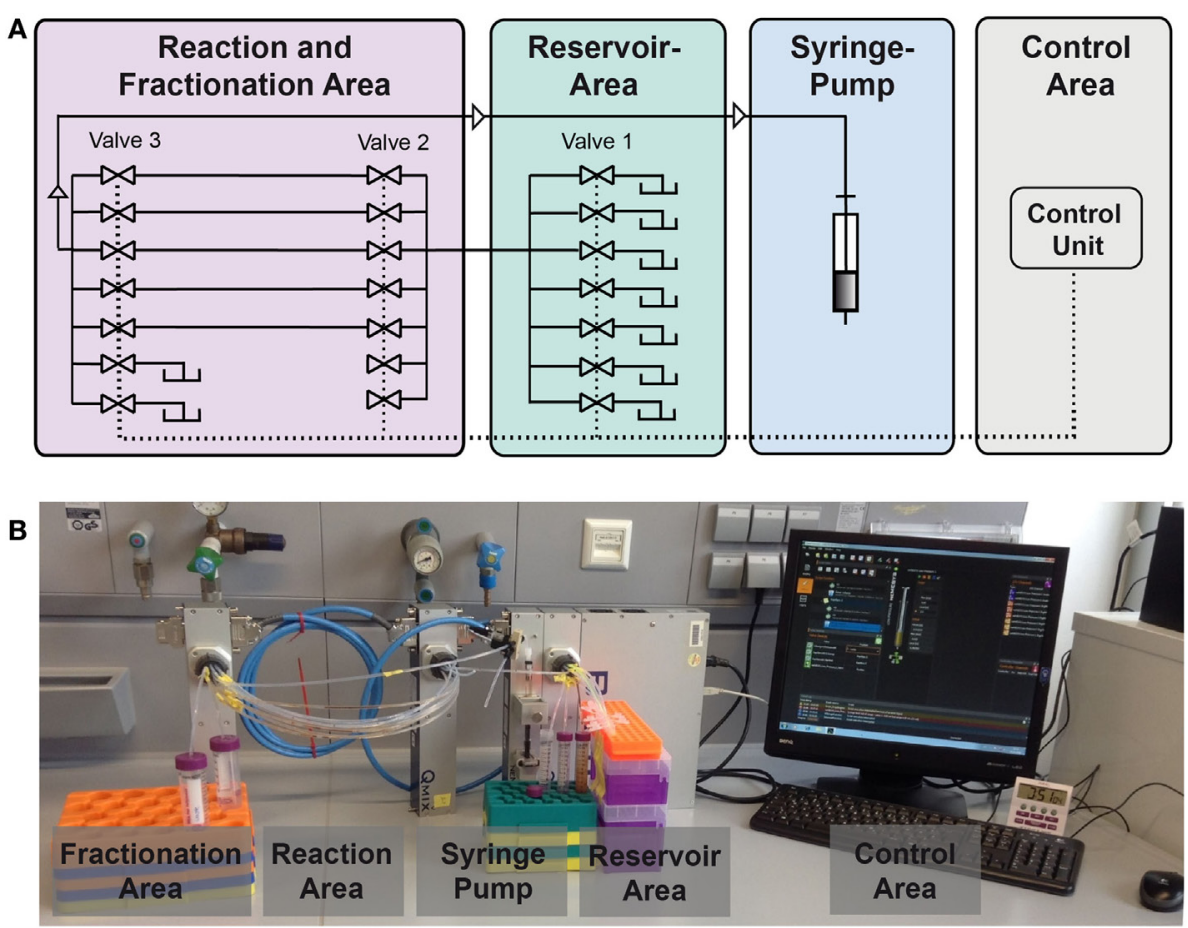

FIGURE 3 | Setup of the compartmented reactor system. (A) Scheme showing the different areas. (B) Photo showing the actual system.

eGFP as a sensor for pepsin activity (Malik et al., 2005). Before the MALDI-TOF analysis could be used for process validation, the applicability of a solid-phase digest by pepsin needed to be verified. The digest of free and immobilized protein was compared, in order to prove that the reaction is similarly efficient. Samples were prepared as described in Section "Digest of Free and Immobilized Protein" and measured via MALDI in the reflector mode. By use of "MASCOT Peptide Mass Fingerprint" and adjustment of the search parameters peptide tolerance (altered between 1-2 Da) and missed cleavages (altered between 0 and 2) the samples were assigned to GFP. Due to the high sequence identity of GFP and eGFP of $98.8 \%$, a successful solid-phase digest and assignment can be assumed for both reactions. The sequence of the used eGFP clone is given in the Supplementary Material.

In order to further compare the digest of the free and the immobilized protein, protein sequence coverage was considered. This value is given by the software during analysis. For this value, the peptides identified during the mass spectrometric measurements are aligned with the amino acid sequence of the considered protein. The protein sequence coverage specifies the portion of amino acids that was covered during this alignment. Therefore, it expresses the efficiency of the digest and detection. For the digest of the free and immobilized protein, this value should be as similar as possible. A protein sequence coverage of 0.53 was determined for the immobilized and 0.56 for the free protein with a peptide tolerance of $0.2 \mathrm{Da}$ and one missed cleavage. These values are very close. Thus, the digest appears to be similarly effective in both systems.

\section{Analysis of Modification Sites}

In the preceding section, it was shown that eGFP can be successfully digested in a solid-phase reaction with an efficiency equal to the digest of free protein. Consequently, an enzymatic digest followed by mass spectrometry can be used to analyze and optimize the reaction conditions for solid-phase biotinylation of eGFP. In a first series of experiments different biotin-excesses were examined, followed by a second series in which the reaction $\mathrm{pH}$ was varied.

\section{Modification with Different Biotin-Excesses}

In this experimental series, the biotin excess was varied by applying a molar ratio of $10,20,50$, and 100 relative to the applied $0.1 \mathrm{mg}$ immobilized eGFP. After the coupling, the reaction products were digested in parallel and the exact positions of the generated modification were determined following the protocol in Section "Protein Modification Reactions." The list of modified lysines depending on the applied excess is given in Table 1. NHSbiotin attacks mainly amines, e.g., lysines or the N-terminus of the protein. As the His-tag of the eGFP is located at the N-terminus, biotinylation of the $\mathrm{N}$-terminus is not regarded here. From the list it becomes clear that the lysines are modified in a sorted way: If a lysine is modified for a smaller biotin-excess, it is also modified with a higher excess. This indicates that the order of modification is not random. Additionally, the higher the excess of NHS-Biotin, the more lysines are modified, as was expected.

Using free protein, a higher number of lysines was modified for almost each case. Consequently, solid-phase biotinylation reduces the extent of biotinylation which is probably due to steric 
TABLE 1 | Modified lysines for the biotinylation with different excesses of biotin-N-hydroxysuccinimide.

\begin{tabular}{|c|c|c|c|c|c|c|c|}
\hline \multicolumn{4}{|c|}{ Different excesses } & \multicolumn{4}{|c|}{ Different excesses } \\
\hline \multicolumn{4}{|c|}{ Solid-phase reaction } & \multicolumn{4}{|c|}{ Reaction with free protein } \\
\hline $10 \times$ & $20 \times$ & $50 \times$ & $100 x$ & $10 \times$ & $20 x$ & $50 \times$ & $100 \times$ \\
\hline K 79 & K79 & K26 & K26 & K26 & K26 & K26 & K26 \\
\hline K 107 & K85 & K79 & K79 & K85 & K85 & K79 & K79 \\
\hline K 113 & K107 & K107 & K85 & K107 & K101 & K85 & K85 \\
\hline K 156 & K113 & K113 & K107 & $\mathrm{K} 113$ & K107 & K101 & K101 \\
\hline K 158 & K126 & K126 & K113 & K126 & K113 & K107 & K107 \\
\hline \multirow[t]{10}{*}{ K 162} & K131 & K131 & K126 & K140 & K126 & K113 & K113 \\
\hline & K156 & K140 & K131 & K209 & K131 & K126 & K126 \\
\hline & K158 & K156 & K140 & K214 & K140 & K131 & K131 \\
\hline & K162 & K158 & K156 & & K166 & K140 & K140 \\
\hline & K209 & K162 & K158 & & K214 & K156 & K156 \\
\hline & K214 & K209 & K162 & & & K158 & K158 \\
\hline & & K214 & K209 & & & K162 & K162 \\
\hline & & & K214 & & & K166 & K166 \\
\hline & & & & & & K214 & K209 \\
\hline & & & & & & & K214 \\
\hline
\end{tabular}

hindrance and reduced accessibility of reaction sites. In addition, temporary fixation of the substrate onto the solid-phase strongly reduces its mobility and, therefore, the collision probability between the protein and NHS-PEG. In consequence the reaction rate is reduced which may also lead to a smaller number of modified lysines. For a preferably complete conversion high excesses of NHS-biotin are thus necessary. The difference in the number of modified lysines ranged from two to four. On the one hand, this indicates a lower efficiency for the solid-phase reaction. On the other hand, this can be regarded as a step toward a more specific biotinylation reaction via NHS-biotin, since a more homogenous product is formed. This can be advantageous for certain applications. However, as MALDI-TOF as qualitative method was chosen for analysis, no quantitative conclusions can be drawn which would deliver further information.

The solid-phase reaction also did not only reduce the number of modified lysines but also changed their composition: K101 and K166 were only modified in solution and not in the solid-phase reaction. Thus, by use of the solid-phase reaction certain lysines can be excluded from the modification reaction which can be useful for reaction control. Possible causes for this are shielding of amino acids by the particle surface and steric effects close to the carrier. Maiser et al. (2015) observed a change in the isoform composition after comparing solid-phase PEGylation with PEGylation of free protein. They were able to lead this difference back to steric effects. However, the PEG applied in this study was larger $(\mathrm{kDa})$ than the biotin used here so that steric hindrance has a smaller effect.

To our knowledge, these experiments represent the first reaction cascade combining protein modification and enzymatic digest, thus sample preparation, in a compartmented microfluidic device.

\section{Modification at Different $\mathrm{pH}$-Values}

In a second set of experiments the influence of the $\mathrm{pH}$-value on solid-phase biotinylation was investigated. As the NHS-group

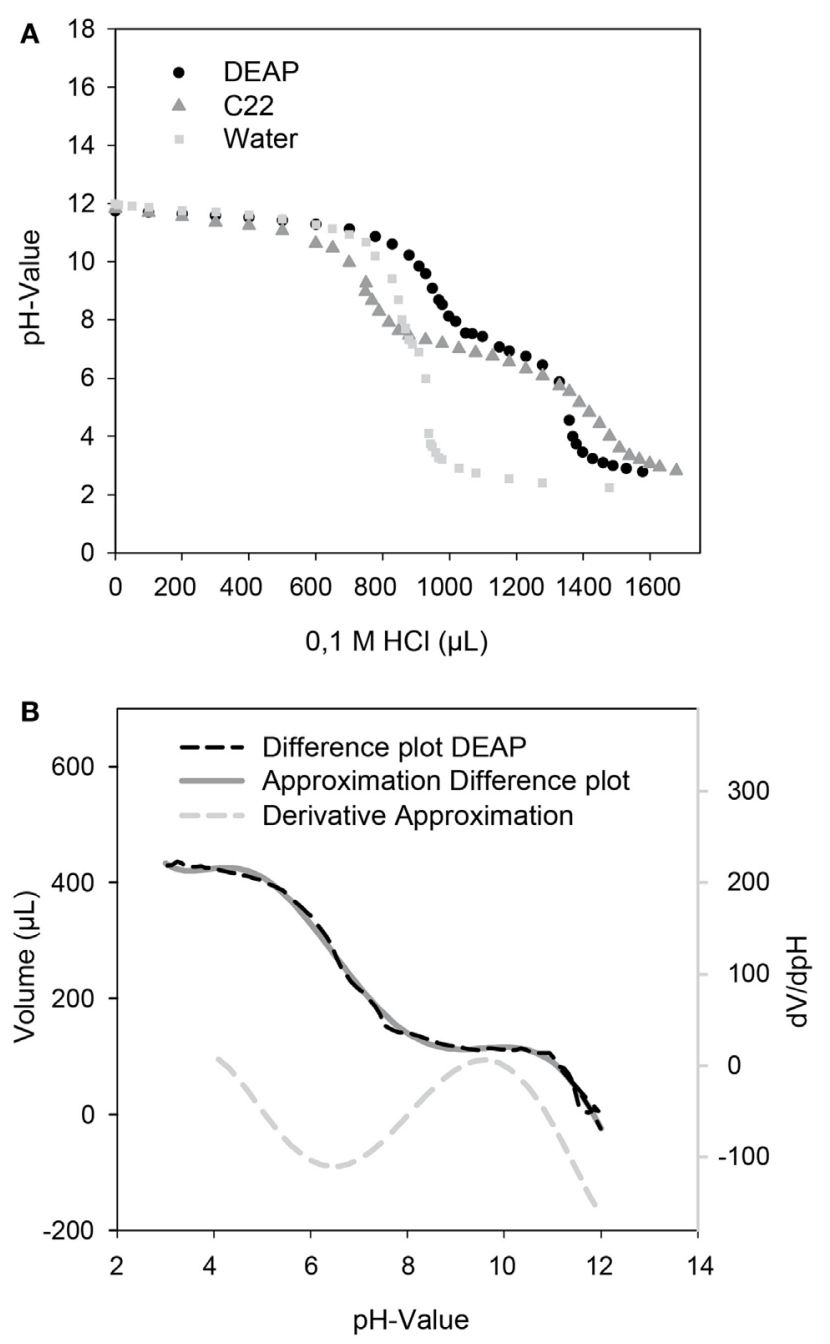

FIGURE 4 | (A) Titration curves of the DEAP, C22 particles, and water as control. $20 \mathrm{mg}$ particles in $10 \mathrm{~mL}$ of a solution of $0.01 \mathrm{M} \mathrm{NaOH}$ were titrated with $0.1 \mathrm{M} \mathrm{HCl}$. (B) For determination of an additional pKa of the DEAP particles, a difference plot of the DEAP and water titration curve was created and derived.

is subject to $\mathrm{pH}$-dependent hydrolysis, which might falsify the results, we first investigated a method for an in situ change of the $\mathrm{pH}$ in the reactor. By changing the $\mathrm{pH}$-value right before the modification reactions, a $\mathrm{pH}$-dependent hydrolysis of NHS can be minimized.

A unique feature of the developed microfluidic reactor is its capability to transfer magnetic micro particles in and out of the compartmented plugs in which the reaction takes place. Therefore, besides serving as carriers for solid-phase protein modification, other types of magnetic particles can also be used for $\mathrm{pH}$ adjustment. For these magnetic micro particles with carboxy or DEAP, functionalities were used as source or sink of protons. The titration curves for both particles are given in Figure 4. Both particle types possess a plateau between $\mathrm{pH} 6$ and $\mathrm{pH} 7.5$ which leads to a $\mathrm{pKa}$ of ca. 6.75. This $\mathrm{pKa}$ results 


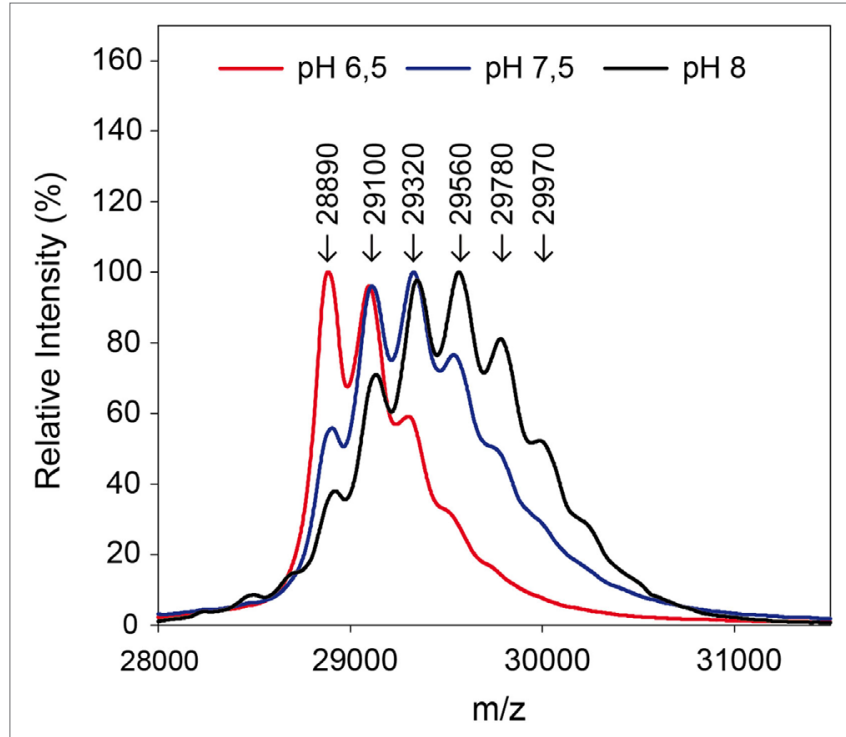

FIGURE 5 | Mass spectra after biotinylation of eGFP at different $\mathrm{pH}$-values. A 20 -fold excess of biotin compared to the used $0.3 \mathrm{mg}$ protein was applied.

from the carboxy groups of the particles. This pKa can also be determined for the DEAP particles as they are synthesized on the basis of the carboxy particles (Müller et al., 2011). It is likely that the conversion was not complete, so that carboxy groups are still present on the surface. Starting at around $\mathrm{pH} 10$, the titration curves of the particle suspensions separate from the titration curve for water. For the DEAP particles this indicates buffering by amine-groups. For the DEAP particles an additional pKa of 9.3 was determined by use of the method by Frimmel et al. (1985). From the titration curves, it can be seen that because of their functional groups the particles are suitable for alteration of the $\mathrm{pH}$-value inside the reactor. Depending on the amount of particles applied, particles with carboxy groups in the protonated form are able to decrease the $\mathrm{pH}$ down to about $\mathrm{pH}$ 6. In contrast, particles with DEAP groups can increase the $\mathrm{pH}$ up to approx. $\mathrm{pH}$ 10. The limited $\mathrm{pH}$-range is caused by the use of weak acids and bases as functional groups. If functional groups with strong dissociation behavior had been used instead, the accessible $\mathrm{pH}-$ range could be strongly enhanced.

By use of the in situ pH-control, solid-phase biotinylation was performed at the $\mathrm{pH}$-values $6.5,7.5$, and 8.0 in the reactor with a 20-fold biotin-excess as described in Section "Protein Modification Reactions." After 5 min reaction time, the reaction plug was withdrawn from the reactor into the fractionation area. Half of the particles were separated and protein was eluted for MALDI measurements in linear mode. The results of the measurements are shown in Figure 5. Subsequently, the enzymatic digest was performed with the remaining particles.

The measurements in linear mode allow for a first characterization of the reaction: a lower $\mathrm{pH}$-value leads to a reduced modification. Fewer biotins were bound to the protein than for higher $\mathrm{pH}$-values, as becomes clear from the lower molecular weights. In the solid-phase reaction, a mass of up to $29,970 \mathrm{Da}$ was measured which corresponds to five coupled biotin molecules.
TABLE 2 | Modified lysines by use of different pH-values for immobilized and free eGFP.

\begin{tabular}{|c|c|c|c|c|c|}
\hline \multicolumn{3}{|c|}{ Different pH-values } & \multicolumn{3}{|c|}{ Different pH-values } \\
\hline \multicolumn{3}{|c|}{ Solid-phase reaction } & \multicolumn{3}{|c|}{ Reaction with free protein } \\
\hline $\mathrm{pH} 6.5$ & $\mathrm{pH} 7.5$ & $\mathrm{pH} 8.0$ & $\mathrm{pH} 6.5$ & $\mathrm{pH} 7.5$ & $\mathrm{pH} 8.0$ \\
\hline K101 & K101 & K26 & K26 & K26 & K26 \\
\hline K107 & K107 & K85 & K107 & K85 & K85 \\
\hline K113 & K113 & K101 & K113 & K107 & K101 \\
\hline K140 & K126 & K107 & K126 & $\mathrm{K} 113$ & K107 \\
\hline K209 & K131 & K113 & K140 & K126 & K113 \\
\hline \multirow[t]{8}{*}{ K214 } & K140 & K126 & K209 & K140 & K126 \\
\hline & K156 & K131 & K214 & K156 & K131 \\
\hline & K158 & K140 & & K158 & K140 \\
\hline & K162 & K156 & & K162 & K156 \\
\hline & K214 & K158 & & K209 & K158 \\
\hline & & K162 & & K214 & K162 \\
\hline & & K209 & & & K209 \\
\hline & & K214 & & & K214 \\
\hline
\end{tabular}

The ratio of modified to unmodified protein (mass of about $28,890 \mathrm{Da}$ ) gives a relative impression of the extent of the yield. The higher the $\mathrm{pH}$-value the less unmodified protein is present. Apparently, the reaction is accelerated at higher $\mathrm{pH}$-values. This is in accordance with literature (Nojima et al., 2009; Maiser et al., 2014). For more detailed information, the samples were also digested by pepsin and then measured by MALDI in reflector mode and with MS/MS, in order to identify the modified amino acids. The modified lysines are given in Table 2 . As in the experiment with different biotin-excesses, the modified biotins appear in a sorted way: If a lysine is modified at a lower $\mathrm{pH}$-value, it also is for a higher value. It should be mentioned that this is not necessarily the case, e.g., for coupling with aldehydes, it has been observed that the modified lysines alter depending on the $\mathrm{pH}$ value (Maiser et al., 2014).

As can be seen in Table 2, the modified lysines also indicate that a higher $\mathrm{pH}$-value leads to an increased biotinylation both for free and immobilized protein. Regarding the modified lysines, the differences between the solid-phase reaction and reaction with dissolved protein are less significant than for the experiments using different excesses of NHS-biotin. This might be due to the shorter reaction time used for the $\mathrm{pH}$-experiments ( $5 \mathrm{~min}$ instead of $60 \mathrm{~min}$ for different excesses). A longer reaction time might lead to a higher number and a higher variety of modified amino acids.

The number of coupled biotins is not equal for the measurement in linear and in reflector mode. One reason for this is the formation of isomers: Despite the same number of bound biotins, different eGFP molecules apparently have the biotins bound to different positions. As consequence, more modified lysines were measured altogether than bound per eGFP in the reflector mode.

\section{CONCLUSION}

In this study, we were able to enhance and apply a compartmented, microfluidic reactor for protein modification reactions and subsequent sample preparation for detailed analysis of the 
reaction products. On the one hand, it was possible to parallelize the reactor so that multiple experiments were feasible in parallel. On the other hand, the reactor could be applied for the screening of different reaction conditions: $\mathrm{pH}$-value, and the excess of NHS-biotin was varied. Modification was directly coupled with enzymatic digest and, thus, with sample preparation. A detailed analysis of the modified lysines was possible by use of mass spectrometric methods.

As expected, a higher excess of NHS-biotin and a higher $\mathrm{pH}-$ value lead to an increased conversion. Additionally, the modified lysines appeared to react in a specific order. Furthermore, it was observed that the modification of immobilized proteins varied from the respective modification of free proteins in the amount of modified lysines, but partly also in the location of the modification. Both aspects might be useful for process control.

Reactant concentration and $\mathrm{pH}$-value were screened in this study, but also other conditions like reaction duration are possible. The same is valid for the reaction types which can be studied: Various modification reactions in aqueous buffer are thinkable in the reactor and besides biotinylation also PEGylation has been investigated in a former study with a simpler version of the reactor. As was additionally shown, enzymatic solid-phase reactions are also possible within the system. Thus, in future a wide range of more complex solid-phase reactions can be

\section{REFERENCES}

Alkaabi, K. M., Yafea, A., and Ashraf, S. S. (2005). Effect of pH on thermal- and chemical-induced denaturation of GFP. Appl. Biochem. Biotechnol. 126, 149-156. doi:10.1385/ABAB:126:2:149

Ballou, B., Fisher, G. W., Waggoner, A. S., Farkas, D. L., Reiland, J. M., Jaffe, R., et al. (1995). Tumor labeling in vivo using cyanine-conjugated monoclonal antibodies. Cancer Immunol. Immunother. 41, 257-263. doi:10.1007/BF01517001

Boutureira, O., and Bernardes, G. J. L. (2015). Advances in chemical protein modification. Chem. Rev. 115, 2174-2195. doi:10.1021/cr500399p

Chiang, C. F., Okou, D. T., Griffin, T. B., Verret, C. R., and Williams, M. N. V. (2001). Green fluorescent protein rendered susceptible to proteolysis: positions for protease-sensitive insertions. Arch. Biochem. Biophys. 394, 229-235. doi:10.1006/ abbi.2001.2537

Diamandis, E. P., and Christopoulos, T. K. (1991). The biotin-(strept)avidin system: principles and applications in biotechnology. Clin. Chem. 37, 625-636.

Frimmel, F. H., Hopp, W., and Quentin, K. E. (1985). Titration isolierter aquatischer Huminstoffe und ihrer Calcium-Komplexe mit starken Basen und Säuren. Z. Wasser Abwasser Forsch. 18, 259-262.

Gillespie, P. G., and Hudspeth, A. J. (1991). Chemiluminescence detection of proteins from single cells. Proc. Natl. Acad. Sci. U.S.A. 88, 2563-2567. doi:10.1073/ pnas.88.6.2563

Green, N. M. (1975). Avidin. Adv. Protein Chem. 29, 85-133. doi:10.1016/S00653233(08)60411-8

Guesdon, J. L., Ternynck, T., and Avrameas, S. (1979). The use of avidin-biotin interaction in immunoenzymatic techniques. J. Histochem. Cytochem. 27, 1131-1139. doi:10.1177/27.8.90074

Han, H. S., Niemeyer, E., Huang, Y., Kamoun, W. S., Martin, J. D., Bhaumik, J., et al. (2015). Quantum dot/antibody conjugates for in vivo cytometric imaging in mice. Proc. Natl. Acad. Sci. U.S.A. 112, 1350-1355. doi:10.1073/ pnas. 1421632111

Hermanson, G. T. (2013). “Chapter 3 - The Reactions of Bioconjugation,” in Bioconjugate Techniques, 3rd Edn. (Boston: Academic Press), 229-258.

Hübner, J., Brakowski, R., Wohlgemuth, J., Brenner-Weiß, G., and Franzreb, M. (2015). Compartmented microfluidic bioreactor system using magnetic enzyme immobilisates for fast small-scale biotransformation studies. Eng. Life Sci. 15, 721-726. doi:10.1002/elsc.201400171 performed in the reactor, like, e.g., glycosylation of immobilized proteins.

\section{AUTHOR CONTRIBUTIONS}

MF, the leader of the research group, contributed to the work by giving the idea for this project, helping in the case of scientific problems and writing parts of the manuscript. RF was the scientist responsible for planning and performing experiments and also writing the main part of the manuscript. JD performed a great part of the experiments and gave valuable input during writing the manuscript.

\section{FUNDING}

The authors would like to acknowledge the federal ministry of education and research, Germany (BMBF) and the project Biotechnologie 2020 + "SeleKomM" for their financial support.

\section{SUPPLEMENTARY MATERIAL}

The Supplementary Material for this article can be found online at http://www.frontiersin.org/article/10.3389/fbioe.2017.00072/ full\#supplementary-material.

Hutsell, S. Q., Kimple, R. J., Siderovski, D. P., Willard, F. S., and Kimple, A. J. (2010). High-affinity immobilization of proteins using biotin- and GST-based coupling strategies. Methods Mol. Biol. 627, 75-90. doi:10.1007/978-1-60761-670-2_4

Maiser, B., Baumgartner, K., Dismer, F., and Hubbuch, J. (2015). Effect of lysozyme solid-phase PEGylation on reaction kinetics and isoform distribution. J. Chromatogr. B Analyt. Technol. Biomed. Life Sci. 1002, 313-318. doi:10.1016/j. jchromb.2015.08.027

Maiser, B., Dismer, F., and Hubbuch, J. (2014). Optimization of random PEGylation reactions by means of high throughput screening. Biotechnol. Bioeng. 111 104-114. doi:10.1002/bit.25000

Malik, A., Rudolph, R., and Söhling, B. (2005). Use of enhanced green fluorescent protein to determine pepsin at high sensitivity. Anal. Biochem. 340, 252-258. doi:10.1016/j.ab.2005.02.022

McMahon, R. J. (2002). Biotin in metabolism and molecular biology. Annu. Rev. Nutr. 22, 221-239. doi:10.1146/annurev.nutr.22.121101.112819

Morgenstern, J., Baumann, P., Brunner, C., and Hubbuch, J. (2017). Effect of PEG molecular weight and PEGylation degree on the physical stability of PEGylated lysozyme. Int. J. Pharm. 519, 408-417. doi:10.1016/j.ijpharm. 2017.01.040

Müller, C., Wagner, K., Frankenfeld, K., and Franzreb, M. (2011). Simplified purification of equine chorionic gonadotropin (eCG) - an example of the use of magnetic microsorbents for the isolation of glycoproteins from serum. Biotechnol. Lett. 33, 929-936. doi:10.1007/s10529-010-0512-5

Nojima, Y., Iguchi, K., Suzuki, Y., and Sato, A. (2009). The pH-dependent formation of PEGylated bovine lactoferrin by branched polyethylene glycol (PEG)N-hdroxysuccinimide (NHS) active esters. Biol. Pharm. Bull. 32, 523-526. doi:10.1248/bpb.32.523

Paulus, A., Till, N., and Franzreb, M. (2015). Controlling the partitioning behavior of magnetic micro-particles via hydrophobization with alkylamines: tailored adsorbents for continuous bioseparation. Appl. Surf. Sci. 332, 631-639. doi:10.1016/j.apsusc.2015.01.161

Perkins, D. N., Pappin, D. J. C., Creasy, D. M., and Cottrell, J. S. (1999). Probabilitybased protein identification by searching sequence databases using mass spectrometry data. Electrophoresis 20, 3551-3567. doi:10.1002/(SICI)1522-2683 (19991201)20:18<3551::AID-ELPS3551>3.0.CO;2-2

Press, A. T., Ungelenk, L., Rinkenauer, A. C., Gröger, M., Lehmann, F., Mosig, A., et al. (2016). A new fluorescent dye for cell tracing and 
mitochondrial imaging in vitro and in vivo. J. Biophotonics 9, 888-900. doi:10.1002/jbio. 201500190

Sokalingam, S., Madan, B., Raghunathan, G., and Lee, S. G. (2013). In silico study on the effect of surface lysines and arginines on the electrostatic interactions and protein stability. Biotechnol. Bioprocess Eng. 18, 18-26. doi:10.1007/ s12257-012-0516-1

Stipanuk, M. H., and Caudil, M. A. (2012). Biochemical, Physiological, and Molecular Aspects of Human Nutrition. Oxford: Elsevier Ltd.

Strohalm, M., Kavan, D., Novák, P., Volný, M., and Havlíček, V. (2010). MMass 3: a cross-platform software environment for precise analysis of mass spectrometric data. Anal. Chem. 82, 4648-4651. doi:10.1021/ac100818g

Tang, X., and Bruce, J. E. (2009). Chemical cross-linking for protein-protein interaction studies. Methods Mol. Biol. 492, 283-293. doi:10.1007/978-1-59745493-3_17

Wilkins, M. R., Lindskog, I., Gasteiger, E., Bairoch, A., Sanchez, J. C., Hochstrasser, D. F., et al. (1997). Detailed peptide characterization using PEPTIDEMASS a World-Wide-Web-accessible tool. Electrophoresis 18, 403-408. doi:10.1002/ elps.1150180314

Wilms, B., Hauck, A., Reuss, M., Syldatk, C., Mattes, R., Siemann, M., et al. (2001). High-cell-density fermentation for production of L-N-carbamoylase using an expression system based on the Escherichia coli rhaBAD promoter. Biotechnol. Bioeng. 73, 95-103. doi:10.1002/bit.1041

Wu, Y., and Goody, R. S. (2010). Probing protein function by chemical modification. J. Pept. Sci. 16, 514-523. doi:10.1002/psc. 1287

Xiao, J., Burn, A., and Tolbert, T. J. (2008). Increasing solubility of proteins and peptides by site-specific modification with betaine. Bioconjug. Chem. 19, 1113-1118. doi:10.1021/bc800063k

Conflict of Interest Statement: The authors declare that the research was conducted in the absence of any commercial or financial relationships that could be construed as a potential conflict of interest.

The reviewer, MJ, and handling editor declared their shared affiliation.

Copyright $\odot 2017$ Fraas, Diehm and Franzreb. This is an open-access article distributed under the terms of the Creative Commons Attribution License (CC BY). The use, distribution or reproduction in other forums is permitted, provided the original author(s) or licensor are credited and that the original publication in this journal is cited, in accordance with accepted academic practice. No use, distribution or reproduction is permitted which does not comply with these terms. 